\title{
Ileocolonoscopic findings in patients with anky- losing spondylitis: a single center retrospective study
}

\author{
Soo Min Ahn ${ }^{1}$, Yong-Gil Kim¹, Seung-Hyeon Bae ${ }^{1}$, Doo-Ho Lim ${ }^{1}$, Seokchan Hong ${ }^{1}$, Sang Hyoung Park², \\ Chang-Keun Lee ${ }^{1}$, and Bin Yoo ${ }^{1}$
}

Divisions of ${ }^{1}$ Rheumatology and ${ }^{2}$ Gastroenterology, Department of Internal Medicine, Asan Medical Center, University of Ulsan College of Medicine, Seoul, Korea

Received: September 15, 2015 Revised : November 25, 2015 Accepted: December 18, 2015

\section{Correspondence to}

Yong-Gil Kim, M.D.

Division of Rheumatology,

Department of Internal

Medicine, Asan Medical Center,

University of Ulsan College of

Medicine, 88 Olympic-ro 43-gil,

Songpa-gu, Seoul 05505, Korea

Tel: +82-2-3010-3279

Fax: +82-2-3010-6969

E-mail: bestmd2000@amc.seoul.kr
Background/Aims: In some Western countries, up to $50 \%$ of patients with ankylosing spondylitis (AS) have subclinical gut inflammation. This study was conducted to evaluate the prevalence and severity of gut inflammation and to determine clinical factors associated with colonic inflammation in Korean AS patients who performed ileocolonoscopy without evidence of established inflammatory bowel diseases before.

Methods: One hundred and eight AS patients who underwent ileocolonoscopy were included in this study. Patients were divided into two groups based on gross ileocolonoscopic findings; patients with inflammatory lesions, and patients without inflammatory lesions.

Results: Inflammatory lesions in ileocolonoscopic findings were found in 40 patients. The Ankylosing Spondylitis Disease Activity Score C-reactive protein was higher in the group with inflammatory lesions and gut lesions were found often in the terminal ileum. The risk of inflammatory lesions was higher for AS patients whose symptoms required ileocolonoscopy than for AS patients who underwent routine ileocolonoscopy screening (odds ratio, 3.96). However, abnormal lesions were detected also in $17.6 \%$ of the patients who underwent ileocolonoscopy for routine screening and most of them were erosion and ulcer. Among patients with inflammatory lesions $(n=40), 23$ showed subclinical gut inflammation associated with AS and 17 were diagnosed finally as Crohn's disease $(n=12)$, intestinal tuberculosis $(n=4)$, and ulcerative colitis $(n=1)$.

Conclusions: Our findings suggest that ileocolonoscopy might be recommended regularly in AS patients even without gastrointestinal symptoms, especially in the patients with high AS activity.

Keywords: Spondylitis, ankylosing; Colonoscopy; Inflammatory bowel diseases; Gastrointestinal diseases

\section{INTRODUCTION}

Ankylosing spondylitis(AS) is the most common subtype of spondyloarthritis (SpA), and is a chronic multisystem- ic inflammatory disorder predominantly affecting the axial skeleton. It is characterized by inflammatory back pain, sacroiliitis, arthritis of the large-bearing joints, and enthesopathy. The most common extra-articular 
manifestations in AS patients include uveitis, psoriasis, and inflammatory bowel disease (IBD) [1].

The prevalence of concurrent AS and IBD, either Crohn's disease (CD) or ulcerative colitis (UC), is estimated to be $5 \%$ to $10 \%$ [2-5]. Significant clinical and genetic overlap between AS and IBD has been reported [6-8]. Also clinical features of SpA may be an extraintestinal manifestation of IBD. Previous studies suggest that radiographic sacroiliitis in IBD patients is often asymptomatic, unilateral and weakly related to human leukocyte antigen (HLA)-B27 [9,10]. Ileocolonoscopy has revealed subclinical gut inflammation in up to $50 \%$ of AS patients, although the majority of these studies included asymptomatic AS patients living in Western countries [11-13]. There have been few studies that have investigated gastrointestinal symptoms or signs and gut inflammation in AS patients by ileocolonoscopy.

The aims of this study were to evaluate the prevalence and severity of gut inflammation by ileocolonoscopy and to determine clinical factors associated with colonic inflammation in South Korean AS patients who have never diagnosed IBD before.

\section{METHODS}

\section{Patients}

We retrospectively reviewed the medical records of 108 patients with AS who underwent ileocolonoscopy for the first time between January 2000 and April 2014 at a tertiary referral hospital in South Korea. All patients fulfilled the modified New York criteria for AS [14]. Patients with previously diagnosed CD, UC, intestinal tuberculosis, or colon cancer were excluded.

Patients were divided into two groups based on ileocolonoscopic results. The first group comprised patients with inflammatory lesions, including ulceration, erosion, erythema, or loss of vascularity. The second group comprised patients without inflammatory lesions and included normal findings, colon polyps, hemorrhoids, or diverticulum. Biopsy specimens were taken from patients with gut inflammation. Ileocolonoscopy was performed by an experienced gastroenterologist.

\section{Demographic data and clinical characteristics}

The clinical characteristics of patients with inflamma- tory lesions were compared to those of patients without inflammatory lesions. Baseline characteristics such as age, sex, underlying disease, medication history, presence of HLA-B27 and inflammatory markers were evaluated. The Ankylosing Spondylitis Disease Activity Score and C-reactive protein (ASDAS-CRP) were used to evaluate disease activity [15]. Patients were divided into three groups according to nonsteroidal anti-inflammatory drug (NSAIDs) use: a continuous-use group comprising patients who used NSAIDs at the time of ileocolonoscopy or within 1 week before, an intermittent-use group (at intervals), and a never-use group. Ileocolonoscopy was performed as part of a regular health checkup, or because of abdominal pain, rectal bleeding, diarrhea, constipation, anemia, and a positive fecal occult blood test. The inflammatory lesions were located in the terminal ileum, cecum, ascending colon, transverse colon, descending colon, sigmoid colon, or rectum. The data were collected from a large clinical electronic database. The study protocol was reviewed and approved by the Asan Medical Center Institutional Review Board (20150314).

\section{Statistical analysis}

Data are expressed as the mean \pm standard deviation (SD) or median (interquartile range). Categorical data are expressed as absolute number and percentage. Comparison of the frequencies of various findings among the patients groups was carried out using the Mann-Whitney $U$ test, the chi-square test, or the linear-by-linear association test. Odds ratios (ORs) were reported with $95 \%$ confidence intervals (CIs). A $p<0.05$ was considered to be statistically significant. Statistical analyses were performed using the SPSS software version 21.0 (IBM Co., Armonk, NY, USA).

\section{RESULTS}

\section{Clinical characteristics of patients with ankylosing spondylitis}

Of the 108 patients who underwent ileocolonoscopy between January 2000 and April 2014, inflammatory lesions were identified in 40 patients (37\%). Demographic data and baseline clinical characteristics of the patients at the time of ileocolonoscopy are shown in Table 1. 
Table 1. Demographic data and baseline clinical characteristics of patients with ankylosing spondylitis

\begin{tabular}{|c|c|c|c|}
\hline Characteristic & Inflammatory lesion $(+)(n=40)$ & Inflammatory lesion $(-)(n=68)$ & $p$ value \\
\hline Age, yr & $36.9 \pm 11.9$ & $41.9 \pm 13.5$ & 0.017 \\
\hline Male sex & $33(82.5)$ & $53(77.9)$ & NS \\
\hline Disease duration, mon & $52.4 \pm 54.1$ & $62.9 \pm 80.4$ & NS \\
\hline History of uveitis & $8(20.0)$ & $14(20.6)$ & NS \\
\hline Family history of AS & $2(5.0)$ & $2(2.9)$ & NS \\
\hline Positive HLA-B27 & $30(78.9)$ & $55(84.6)$ & NS \\
\hline $\mathrm{ESR}, \mathrm{mm} / \mathrm{hr}$ & $39 \cdot 3 \pm 33 \cdot 3$ & $24.1 \pm 21.8$ & 0.014 \\
\hline $\mathrm{CRP}, \mathrm{mg} / \mathrm{dL}$ & $3.14 \pm 4.53$ & $0.72 \pm 1.27$ & 0.002 \\
\hline Mean ASDAS: CRP & $2.77 \pm 1.33$ & $1.94 \pm 0.72$ & 0.001 \\
\hline Back pain & $4.38 \pm 1.89$ & $3.35 \pm 1.49$ & 0.006 \\
\hline Duration of morning stiffness & $3.60 \pm 1.88$ & $2.86 \pm 1.55$ & 0.008 \\
\hline Patient global assessment & $4.10 \pm 1.81$ & $2.88 \pm 1.31$ & $<0.001$ \\
\hline Peripheral pain/swelling & $3.93 \pm 1.90$ & $2.89 \pm 1.36$ & 0.002 \\
\hline ASDAS: CRP activity state & & & $0.001^{\mathrm{a}}$ \\
\hline Inactive $(<1.3)$ & $7(17 \cdot 5)$ & $15(22.1)$ & \\
\hline Moderate $(\geq 1.3 \&<2.1)$ & $7(17 \cdot 5)$ & $29(42.6)$ & \\
\hline $\operatorname{High}(\geq 2.1 \& \leq 3.5)$ & $14(35 \cdot 0)$ & $22(32.4)$ & \\
\hline Very high $(>3.5)$ & $12(30.0)$ & $2(2.9)$ & \\
\hline \multicolumn{4}{|l|}{ Past medical history } \\
\hline Sulfasalazine $\left(\mathrm{n}=3^{8}\right)$ & $11(27 \cdot 5)$ & $27(39.7)$ & NS \\
\hline Methotrexate $(n=13)$ & $4(10.0)$ & $9(13.2)$ & NS \\
\hline Anti-TNF agent $(n=26)$ & $13(32.5)$ & $13(19.1)$ & NS \\
\hline \multicolumn{4}{|l|}{ NSAIDs use } \\
\hline Never-use $(\mathrm{n}=14)$ & $8(20.0)$ & $6(8.8)$ & NS \\
\hline Intermittent-use $(n=44)$ & $15(37 \cdot 5)$ & $29(42.6)$ & NS \\
\hline Continuous-use $(n=50)$ & $17(42 \cdot 5)$ & $33(48.5)$ & NS \\
\hline
\end{tabular}

Values are presented as mean $\pm \mathrm{SD}$ or number (\%).

NS, not significant; AS, ankylosing spondylitis; HLA, human leukocyte antigen; ESR, erythrocyte sediment rate; CRP, Creactive protein; ASDAS, Ankylosing Spondylitis Disease Activity Score; TNF, tumor necrosis factor; NSAID, nonsteroidal antiinflammatory drug.

aTrend analysis (linear-by-linear association) by the categorization of ASDAS-CRP scores.

Patients with inflammatory lesions were younger than patients without inflammatory lesions. However, gender, duration of disease, and the presence of underlying diseases did not differ between both groups. The erythrocyte sediment rate (ESR), CRP level, and ASDAS-CRP score level in the group with inflammatory lesions were significantly higher than those of the group without inflammatory lesions (ESR, $p=0.014$; CRP, $p=0.002$; ASDAS-CRP, $p=0.001$, respectively). The ASDAS-CRP cutoff scores were categorized into four groups based on values of AS disease activity [15]. High or very high AS activity was shown in $65 \%$ of patients with inflammatory gut lesions, while only $35.3 \%$ of patients without them. Trend analysis (linear-by-linear association) on the basis of ASDAS-CRP cut-off scores showed a significant association with inflammatory gut lesions $(p=0.001)$. The use of various drugs such as NSAIDs, sulfasalazine, anti-tumor necrosis factor (TNF) agent or methotrexate, did not differ between patients with inflammatory lesions and patients without inflammatory lesions. 


\section{Ileocolonoscopic findings in patients with AS}

The most common sites involved were the terminal ileum (72.5\%), the rectum (45.0\%), and the cecum (42.5\%) (Table 2). As shown in Table 3, in the 40 patients with inflammatory lesions, loss of vascularity was found in three patients, erythema in five patients, erosion in eight patients, and ulceration in 29 patients grossly. Confirmation of diagnosis in these patients was obtained by biopsy, which revealed CD ( $\mathrm{n}=12), \mathrm{UC}(\mathrm{n}=1)$, intestinal tuberculosis ( $\mathrm{n}=4$, one case with an old scar lesion), and subclinical gut inflammation $(\mathrm{n}=23)$. Ileocolonoscopy revealed ileocolonic ulceration in all 16 patients with $\mathrm{CD}$ and intestinal tuberculosis. All 13 patients with both AS and IBD showed bilateral sacroiliitis on sacroiliac images and $69.2 \%$ of them were positive on HLA-B27, which was not different between patients with and without IBD.

Table 2. Sites of involvement revealed by ileocolonoscopy (n $=40$ )

\begin{tabular}{lc}
\hline Site of involvement & No. of patients (\%) \\
\hline Terminal ileum & $29(72.5)$ \\
Cecum & $17(42.5)$ \\
Ascending colon & $14(35.0)$ \\
Transverse colon & $12(30.0)$ \\
Descending colon & $10(25.0)$ \\
Sigmoid colon & $10(25.0)$ \\
Rectum & $18(45.0)$ \\
Terminal ileum only & $15(37.5)$ \\
Colon only & $11(27.5)$ \\
Terminal ileum \& Colon & $14(35.0)$ \\
\hline
\end{tabular}

\section{Reasons for ileocolonoscopy in AS patients}

In the 108 patients with AS, ileocolonoscopy was performed on 34 patients as a routine screening procedure, whereas it was performed on 74 patients with symptoms or signs of gut inflammation at the time of ileocolonoscopy. Inflammatory lesions were observed in six of 34 patients (17.6\%) who underwent the ileocolonoscopy for screening purposes, and in 34 of 74 patients (45.9\%) who had gastrointestinal symptoms or signs. The most common gastrointestinal symptoms were diarrhea (n = 22), abdominal pain $(\mathrm{n}=2 \mathrm{1})$, and rectal bleeding $(\mathrm{n}=$ 15) (Table 3). AS patients who complained of symptoms or signs requiring ileocolonoscopy had higher risk of inflammatory gut lesions than those subjected to routine ileocolonoscopy without symptoms or signs (OR, 3.96; $95 \%$ CI, 1.47 to $10.71 ; p=0.005$ ). Among various reasons for ileocolonoscopy, abdominal pain was associated with gut inflammation most frequently (61.9\%) and higher risk of gut inflammation than other gastrointestinal symptoms (OR, 3.61; 95\% CI, 1.34 to $9.73 ; p=0.008$ ). Regardless of having gastrointestinal symptoms, ulcer was most frequent inflammatory gut lesion on ileocolonoscopy grossly.

\section{DISCUSSION}

Macroscopic and microscopic ileocolonic inflammation documented by ileocolonoscopy have been described in patients with AS. The prevalence of macroscopic colonic inflammation in ileocolonoscopy from patients with AS has been reported to be $7.8 \%$ to $36 \%$, and $15 \%$ to $80 \%$ in microscopic colonic inflammation [11-13,16-22]. In the

Table 3. Presence of inflammatory lesions with respect to reasons for ileocolonoscopy in patients with ankylosing spondylitis

\begin{tabular}{|c|c|c|c|c|c|c|}
\hline \multirow{2}{*}{ Variable } & \multirow{2}{*}{ No. of patient } & \multirow{2}{*}{$\begin{array}{l}\text { Inflammatory lesions (+), } \\
\mathrm{n}(\%)\end{array}$} & \multicolumn{4}{|c|}{ Ileocolonoscopic findings, lesions no. } \\
\hline & & & Loss of vascularity & Erythema & Erosion & Ulcer \\
\hline Symptoms or signs (-) & 34 & $6(17.6)$ & 1 & $\mathrm{O}$ & 2 & 4 \\
\hline Symptoms or signs (+) & 74 & $34(45 \cdot 9)$ & 2 & 5 & 6 & 25 \\
\hline Diarrhea & 22 & $10(45 \cdot 5)$ & $\mathrm{O}$ & 2 & 1 & 7 \\
\hline Abdominal pain & 21 & $13(61.9)$ & 1 & 3 & 2 & 10 \\
\hline Rectal bleeding & 15 & $5(33 \cdot 3)$ & $\mathrm{O}$ & $\mathrm{O}$ & 2 & 4 \\
\hline Anemia & 8 & $4(50.0)$ & $\mathrm{O}$ & o & 1 & 3 \\
\hline Stool occult blood (+) & 5 & $1(20.0)$ & $\mathrm{O}$ & o & $\mathrm{O}$ & 1 \\
\hline Constipation & 3 & $1(33 \cdot 3)$ & 1 & 0 & 0 & $\mathrm{O}$ \\
\hline
\end{tabular}


present study, macroscopic inflammation of the colon was found in 40 of 108 patients (37\%) with AS. Similar to previous studies, we found the terminal ileum to be the most common site involved.

One of the aims of the present study was to determine clinical factors associated with colonic inflammation in AS patients in South Korea. In our study, higher serum levels of acute phase reactants (ESR and CRP) were detected in AS patients with inflammatory gut lesions. Furthermore, in accordance with ASDAS-CRP, higher disease activity was associated with inflammatory gut lesions. These findings suggest that macroscopic inflammation of the colon may be associated with high disease activity in AS patients. These findings are contrary to those of a previous study that showed serum levels of acute phase reactants to be similar in patients with AS, regardless of gut inflammation. However, in their study, higher bath AS disease activity index scores were found in patients with gut inflammation than in those without gut inflammation [20].

A recent study showed that in patients with SpA having gut inflammation at baseline, a significantly higher proportion was given anti-TNF agents later because of NSAID failure, high disease activity and elevated CRP [21]. However, in our study, although the patients were alternating between various anti-TNF agents during the follow-up period, no significant difference was found between AS patients with positive inflammatory lesions $(32.5 \%)$ and those without inflammatory lesions (19.1\%). Furthermore, it has been suggested that the use of NSAIDs could result in mucosal damages on the colon, such as erosions, ulcers, strictures, and perforation $[23,24]$, though not yet been ascertained in our data.

Another interesting observation from this study, patients with gastrointestinal symptoms or signs demonstrated a high frequency of inflammatory gut lesions with an OR approximately four times greater than patients without gastrointestinal symptoms or signs. Abdominal pain was most commonly associated with inflammatory ileocolonoscopic findings. Similarly, previous study had found that the inflammatory gut lesions such as mucosal erythema or ulceration were observed more frequently in patients with irritable bowel syndrome than in general populations [25]. Furthermore, AS patients who underwent the ileocolonoscopy for screening purposes in our study showed relatively higher incidence of macroscopic inflammatory lesions (17.6\%) compared to normal population (0.1\% to $3.7 \%$ ) [26-29]. And the severe inflammatory changes including erosion or the ulcer were frequently observed even in the patients without clinical symptoms or signs.

The main limitations of this study include its small sample size and retrospective design. We did not estimate microscopic colonic inflammation in AS patients, as it was not possible to evaluate random colonic biopsies. Despite these shortcomings, our results may be helpful for clinician to make decisions for AS patients with gastrointestinal symptoms.

In conclusion, in our study, inflammatory gut lesions were found in a considerable portion in Korean AS patients who have never been established IBDs before. And, erosion and ulcer were found by colonoscopy, even in some of AS patients without gastrointestinal symptoms. Therefore, regular checkup with ileocolonoscopy might be helpful detecting early inflammatory lesion in AS patients, especially in those with high disease activity.

\section{KEY MESSAGE}

1. Inflammatory gut lesions were frequently found in ankylosing spondylitis (AS) patients, even in patients without gastrointestinal problems.

2. Ileocolonoscopy might be recommended regularly in AS patients even without gastrointestinal symptoms, especially in the patients with high AS activity.

\section{Conflict of interest}

No potential conflict of interest relevant to this article was reported.

\section{Acknowledgments}

This research was supported by the Asan Institute for Life Science (2014-463).

\section{REFERENCES}

1. Braun J, Sieper J. Ankylosing spondylitis. Lancet 2007;369:1379-1390.

2. de Vlam K, Mielants H, Cuvelier C, De Keyser F, Veys EM, De Vos M. Spondyloarthropathy is underestimated in 
inflammatory bowel disease: prevalence and HLA association. J Rheumatol 2000;27:2860-2865.

3. Brophy S, Pavy S, Lewis P, et al. Inflammatory eye, skin, and bowel disease in spondyloarthritis: genetic, phenotypic, and environmental factors. J Rheumatol 2001;28:2667-2673.

4. Purrmann J, Zeidler H, Bertrams J, et al. HLA antigens in ankylosing spondylitis associated with Crohn's disease: increased frequency of the HLA phenotype B27,B44. J Rheumatol 1988;15:1658-1661.

5. Stolwijk C, van Tubergen A, Castillo-Ortiz JD, Boonen A. Prevalence of extra-articular manifestations in patients with ankylosing spondylitis: a systematic review and meta-analysis. Ann Rheum Dis 2015;74:65-73.

6. International Genetics of Ankylosing Spondylitis Consortium (IGAS), Cortes A, Hadler J, et al. Identification of multiple risk variants for ankylosing spondylitis through high-density genotyping of immune-related loci. Nat Genet 2013;45:730-738.

7. Rashid T, Ebringer A. Gut-mediated and HLA-B27-associated arthritis: an emphasis on ankylosing spondylitis and Crohn's disease with a proposal for the use of new treatment. Discov Med 2011;12:187-194.

8. Rudwaleit M, Baeten D. Ankylosing spondylitis and bowel disease. Best Pract Res Clin Rheumatol 2006;20:451-471.

9. Queiro R, Maiz O, Intxausti J, et al. Subclinical sacroiliitis in inflammatory bowel disease: a clinical and follow-up study. Clin Rheumatol 2000;19:445-449.

10. Steer S, Jones H, Hibbert J, et al. Low back pain, sacroiliitis, and the relationship with HLA-B27 in Crohn's disease. J Rheumatol 2003;30:518-522.

11. Van Praet L, Van den Bosch FE, Jacques P, et al. Microscopic gut inflammation in axial spondyloarthritis: a multiparametric predictive model. Ann Rheum Dis 2013;72:414-417.

12. Islam MN, Chowdhury MM, Haq SA, et al. The colon in patients with ankylosing spondylitis and in normal controls in Bangladesh: a macroscopic and microscopic study. Clin Rheumatol 2010;29:13-18.

13. Chowdhury MM, Alim MA, Rashid MH, et al. Colonoscopic findings and histological changes in patients suffering from ankylosing spondylitis with normal bowel habit. J Teach Assoc 2009;22:1-4.

14. van der Linden S, Valkenburg HA, Cats A. Evaluation of diagnostic criteria for ankylosing spondylitis: a proposal for modification of the New York criteria. Arthritis
Rheum 1984;27:361-368.

15. Machado P, Landewe R, Lie E, et al. Ankylosing Spondylitis Disease Activity Score (ASDAS): defining cut-off values for disease activity states and improvement scores. Ann Rheum Dis 2011;70:47-53.

16. Meuwissen SG, Dekker-Saeys BJ, Agenant D, Tytgat GN. Ankylosing spondylitis and inflammatory bowel disease. I. Prevalence of inflammatory bowel disease in patients suffering from ankylosing spondylitis. Ann Rheum Dis 1978;37:30-32.

17. Mielants H, Veys EM, Cuvelier C, de Vos M. Ileocolonoscopic findings in seronegative spondylarthropathies. $\mathrm{Br}$ J Rheumatol 1988;27 Suppl 2:95-105.

18. Leirisalo-Repo M, Turunen U, Stenman S, Helenius P, Seppala K. High frequency of silent inflammatory bowel disease in spondylarthropathy. Arthritis Rheum 1994;37:23-31.

19. Lee YH, Ji JD, Kim JS, et al. Ileocolonoscopic and histologic studies of Korean patients with ankylosing spondylitis. Scand J Rheumatol 1997;26:473-476.

20. Hascelik G, Oz B, Olmez N, et al. Association of macroscopic gut inflammation with disease activity, functional status and quality of life in ankylosing spondylitis. Rheumatol Int 2009;29:755-758.

21. Cypers H, Varkas G, Van Praet L, Van den Bosch F, Elewaut D. Microscopic gut inflammation in SPA is a prognostic factor for initiation of anti-TNF therapy in daily practice. Ann Rheum Dis 2014;73(Suppl 2):121-122.

22. Maleh HC, Bica BE, Papi JA, de Azevedo MN, Carneiro AJ. Colonoscopic evaluation in patients with ankylosing spondylitis. Rev Bras Reumatol 2014;54:342-348.

23. Kwo PY, Tremaine WJ. Nonsteroidal anti-inflammatory drug-induced enteropathy: case discussion and review of the literature. Mayo Clin Proc 1995;70:55-61.

24. Kaufman HL, Fischer AH, Carroll M, Becker JM. Colonic ulceration associated with nonsteroidal anti-inflammatory drugs: report of three cases. Dis Colon Rectum 1996;39:705-710.

25. Chey WD, Nojkov B, Rubenstein JH, Dobhan RR, Greenson JK, Cash BD. The yield of colonoscopy in patients with non-constipated irritable bowel syndrome: results from a prospective, controlled US trial. Am J Gastroenterol 2010;105:859-865.

26. Chang HS, Lee D, Kim JC, et al. Isolated terminal ileal ulcerations in asymptomatic individuals: natural course and clinical significance. Gastrointest Endosc 
2010;72:1226-1232.

27. Zwas FR, Bonheim NA, Berken CA, Gray S. Diagnostic yield of routine ileoscopy. Am J Gastroenterol 1995;90:14411443 .

28. Cherian S, Singh P. Is routine ileoscopy useful? An obser- vational study of procedure times, diagnostic yield, and learning curve. Am J Gastroenterol 2004;99:2324-2329.

29. Jeong SH, Lee KJ, Kim YB, Kwon HC, Sin SJ, Chung JY. Diagnostic value of terminal ileum intubation during colonoscopy. J Gastroenterol Hepatol 2008;23:51-55. 